\title{
MEGAPOLI: concept of multi-scale modelling of megacity impact on air quality and climate
}

\begin{abstract}
A. Baklanov ${ }^{1}$, M. Lawrence ${ }^{2}$, S. Pandis ${ }^{3}$, A. Mahura ${ }^{1}$, S. Finardi ${ }^{4}$, N. Moussiopoulos ${ }^{5}$, M. Beekmann ${ }^{6,7}$, P. Laj ${ }^{6}$, L. Gomes ${ }^{6}$, J.-L. Jaffrezo ${ }^{6}$, A. Borbon ${ }^{7}$, I. Coll ${ }^{7}$, V. Gros ${ }^{8}$, J. Sciare ${ }^{8}$, J. Kukkonen ${ }^{9}$, S. Galmarini ${ }^{10}$, F. Giorgi ${ }^{11}$, S. Grimmond ${ }^{12}$, I. Esau ${ }^{13}$, A. Stohl ${ }^{14}$, B. Denby ${ }^{14}$, T. Wagner ${ }^{2}$, T. Butler ${ }^{2}$, U. Baltensperger ${ }^{15}$, P. Builtjes ${ }^{16}$, D. van den Hout ${ }^{16}$, H. D. van der Gon ${ }^{16}$, B. Collins ${ }^{17}$, H. Schluenzen ${ }^{18}$, M. Kulmala ${ }^{19}$, S. Zilitinkevich ${ }^{19}$, R. Sokhi ${ }^{20}$, R. Friedrich ${ }^{21}$, J. Theloke ${ }^{21}$, U. Kummer ${ }^{21}$, L. Jalkinen ${ }^{22}$,
\end{abstract} T. Halenka ${ }^{23}$, A. Wiedensholer ${ }^{24}$, J. Pyle ${ }^{25}$, and W. B. Rossow ${ }^{25}$

${ }^{1}$ Danish Meteorological Institute (DMI), Lyngbyvej 100, 2100, Copenhagen, Denmark

${ }^{2}$ Max Planck Institute for Chemistry (MPIC), Germany

${ }^{3}$ Foundation for Research and Technology (FORTH), Hellas, University of Patras, Greece

${ }^{4}$ ARIANET Consulting, Italy

${ }^{5}$ Aristotle University Thessaloniki (AUTH), Greece

${ }^{6}$ Centre National de Recherche Scientifique (CNRS), France

${ }^{7}$ Laboratory Inter-universitaire des Systèmes Atmosphériques (LISA), France

${ }^{8}$ Laboratoire des Sciences du Climat et de l'Environnement (LSCE), France

${ }^{9}$ Finnish Meteorological Institute (FMI), Finland

${ }^{10}$ Joint Research Center (JRC), Ispra, Italy

${ }^{11}$ International Centre for Theoretical Physics (ICTP), Italy

${ }^{12}$ King's College London (KCL), UK

${ }^{13}$ Nansen Environmental and Remote Sensing Center (NERSC), Norway

${ }^{14}$ Norwegian Institute for Air Research (NILU), Norway

${ }^{15}$ Paul Scherrer Institute (PSI), Switzerland

${ }^{16}$ TNO-Built Environment and Geosciences, The Netherlands

${ }^{17}$ UK MetOffice (MetO), UK

${ }^{18}$ University of Hamburg (UHam), Hamburg, Germany

${ }^{19}$ University of Helsinki (UHel), Finland

${ }^{20}$ University of Hertfordshire - Centre for Atmospheric \& Instrumentation Research (UH-CAIR), UK

${ }^{21}$ University of Stuttgart (UStutt), Germany

${ }^{22}$ World Meteorological Organization (WMO), Switzerland

${ }^{23}$ Charles University Prague (CUNI), Czech Republic

${ }^{24}$ Institute of Tropospheric Research (IfT), Germany

${ }^{25}$ Centre for Atmospheric Science, University of Cambridge (UCam), UK

Received: 31 December 2009 - Revised: 22 November 2010 - Accepted: 22 November 2010

- Published: 26 November 2010 -

\begin{abstract}
The EU FP7 Project MEGAPOLI: "Megacities: Emissions, urban, regional and Global Atmospheric POLlution and climate effects, and Integrated tools for assessment and mitigation" (http://megapoli. info) brings together leading European research groups, state-of-the-art scientific tools and key players from non-European countries to investigate the interactions among megacities, air quality and climate. MEGAPOLI bridges the spatial and temporal scales that connect local emissions, air quality and weather with global atmospheric chemistry and climate. The suggested concept of multi-scale integrated modelling of megacity impact on air quality and climate and vice versa is discussed in the paper. It requires considering different spatial and temporal dimensions: time scales from seconds and hours (to understand the interaction mechanisms) up to years and decades (to consider the climate effects); spatial resolutions: with model down- and up-scaling from street- to global-scale; and two-way interactions between meteorological and chemical processes.
\end{abstract}




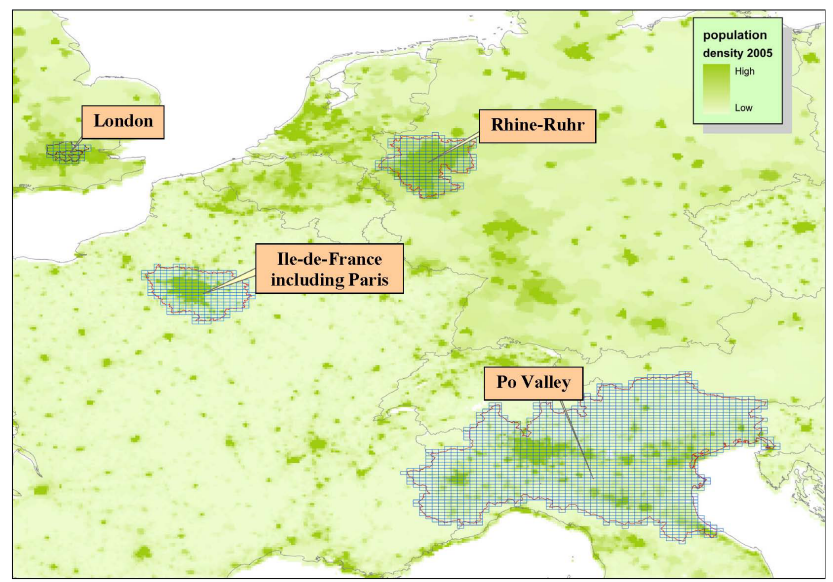

Figure 1. Domain of selected 1st level Megacities in MEGAPOLI (van der Gon et al., 2009).

\section{Introduction}

For the past few hundred years, human populations have been clustering in increasingly large settlements. In 2007, for the first time in history, the world's urban population exceeded the rural population. At present, there are about 20 cities worldwide with a population of $10 \mathrm{mln}$ inhabitants or greater, and 30 with a population of exceeding $7 \mathrm{mln}$ inhabitants. These numbers are expected to grow considerably in the near future. Such coherent urban areas with more than about $5 \mathrm{mln}$ people are usually called megacities (although there is no formal definition of a megacity at present). In Europe there are 6 major population centres that clearly qualified as megacities: London, Paris, the Rhine-Ruhr region, the Po Valley, Moscow, and Istanbul. The first four of them are considered in the project as the 1st level megacities or urban agglomerations in focus (Fig. 1).

\section{Concept and project objectives}

The new EU FP7 Project MEGAPOLI: "Megacities: Emissions, urban, regional and Global Atmospheric POLlution and climate effects, and Integrated tools for assessment and mitigation" (http://megapoli.info) started in October 2008, to investigate the interactions among megacities, air quality and climate. The consortium consists of 23 full main partners from 11 European countries, 12 international research non-funded partners and multiple end-users from Canada, Chile, China, Egypt, France, India, Mexico, Russia, Thailand, Turkey, UK, Ukraine, and USA. The project includes both basic and applied research, and bridges the spatial and temporal scales that connect local emissions, air qual- ity and weather conditions with global atmospheric chemistry and climate. The main objectives are (i) to assess impacts of megacities and large air-pollution hot-spots on local, regional and global air quality, (ii) to quantify feedbacks among megacity air quality, local and regional climate, and global climate change, (iii) to develop improved integrated tools for prediction of air pollution in megacities.

In order to fulfil the objectives the following scientific questions are addressed:

- What is the change of exposure of the overall population to the major air pollutants as people move into megacities? What are the health impacts of this exposure?

- How do megacities affect air quality on regional and global scales? What is the range of influence for major air pollutants (ozone, particulate matter, etc.)?

- What are the major physical and chemical transformations of air pollutants as they are moving away from megacities? What happens to the organic particulate matter, volatile organic compounds, etc.?

- How accurate are the current emission inventories for megacities in Europe and around the world? What are the major gaps?

- How large is the current impact of megacities on regional and global climate?

- How will the growth of megacities affect future climate at global and regional scales?

- What is the impact of large-scale dynamic processes on air pollution from megacities?

- What are the key feedbacks between air quality, local climate and global climate change relevant to megacities? For example, how will climate change affect air quality in megacities?

- How should megacities (emissions, processing inside megacities, meteorology) be parameterised in regional and global models?

- What type of modelling tools should be used for the simulation of multi-scale megacity air quality - climate interactions?

- Which policy options are available to influence the emissions of air pollutants and greenhouse gases in megacities and how can these options be assessed? 


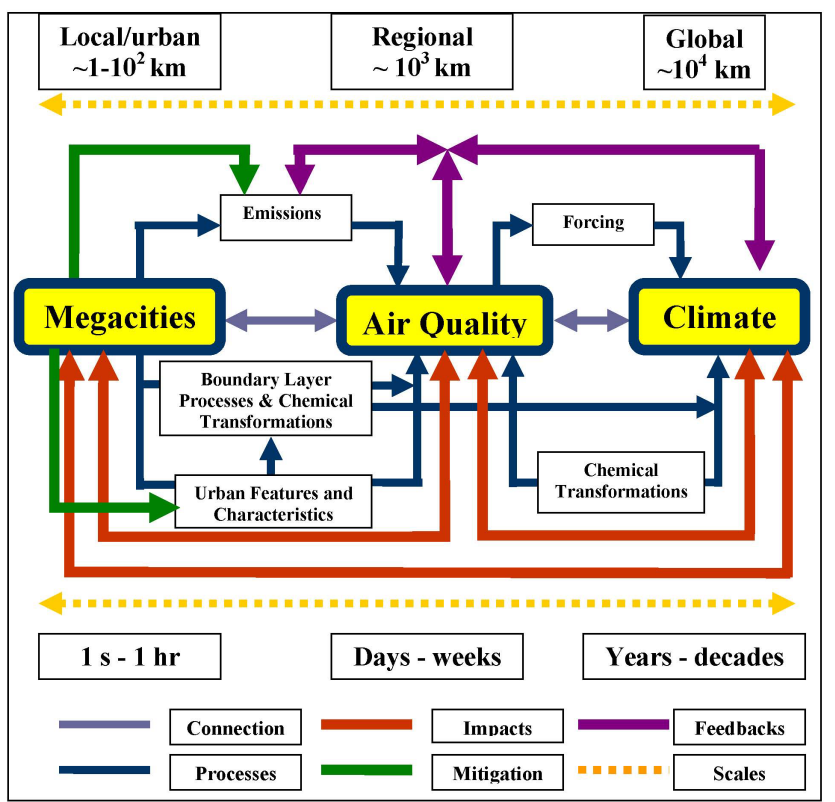

Figure 2. Schematic showing the main linkages between megacities, air quality and climate. The connections and processes will be the focus of MEGAPOLI. In addition to the overall connections between megacities, air quality and climate, the figure shows the main feedbacks, ecosystem, health and weather impact pathways, and mitigation routes which will be investigated. The relevant temporal and spatial scales are additionally included.

\section{Methodology and results}

The project focuses on research spanning the range from emissions to air quality, effects on regional and global climate, and feedbacks and mitigation potentials. The project takes into account different features and growing trends that characterize cities located in developed and developing countries to highlight their present and future effects on local to global air quality and climate (Baklanov and Mahura, 2009).

The proposed hypothesis is that megacities around the world have an impact on air quality not only locally, but also regionally and globally and therefore can also influence the climate of our planet. In Fig. 2 a schematic description of how megacities, air quality and climate interact is presented. Although some of the links shown have already been considered, a complete quantitative picture of these interactions is still missing. Understanding and quantifying of these missing links is the focus of MEGAPOLI.

The first critical step in improving our understanding of how megacities impact air quality, atmospheric composition and climate on different scales is the development of highquality inventories of the emissions of relevant gases and aerosols and their precursors, and determining how these are anticipated to change in the mid-term future, as well as how these change under various scenarios (e.g., relocation of $10 \%$ of the population out of a megacity and into the surrounding

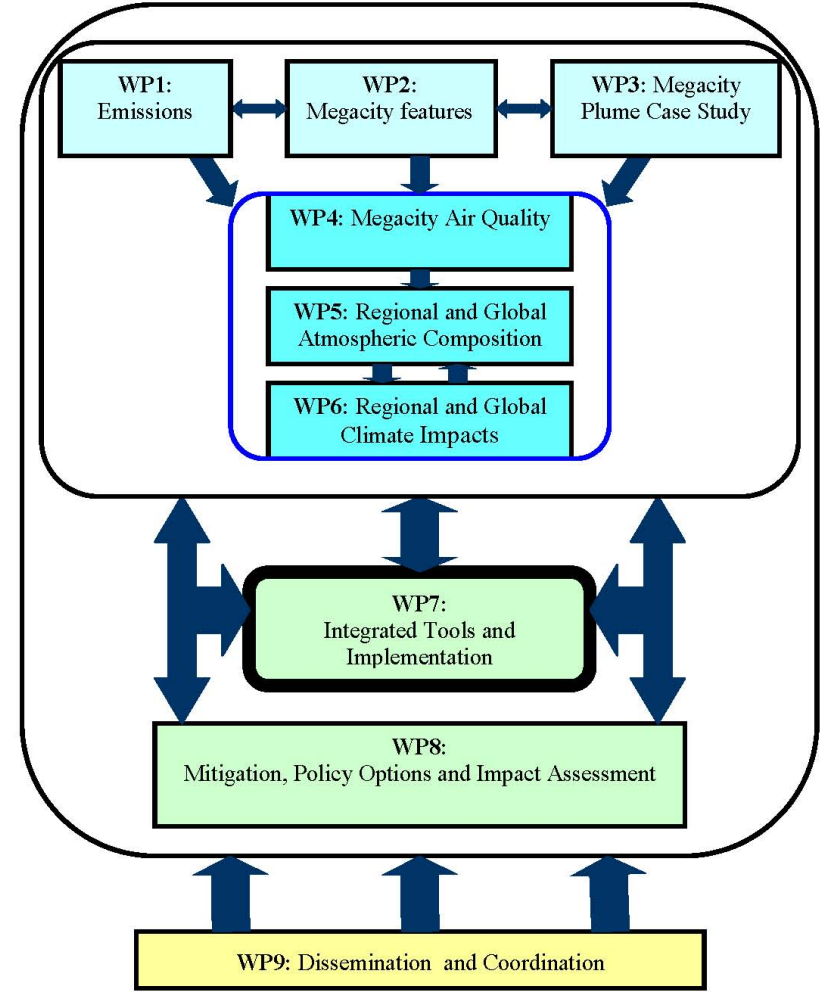

Figure 3. MEGAPOLI Work Packages (WPs) structure and linkage.

countryside). This forms the key input to the remaining components of the study, and will also, through an understanding of the sensitivity of emissions of different compounds and from different sectors, form the basis for sensible approaches to mitigation strategies. This task is used as a starting point with the corresponding emission inventories developed by local administrations for major urban areas. These will be improved when necessary, adjusted to the appropriate model scale and integrated into larger scale datasets for their use in regional and global scale atmospheric composition modelling. This approach allows the exploitation of former investments and available information, and builds connections between local air quality management authorities and the air quality and climate research community. The first version of the MEGAPOLI European gridded emission inventory for the base year 2005 has the resolution of $6 \times 6 \mathrm{~km}$ with nesting up to $1 \times 1 \mathrm{~km}$ inventories for the $1 \mathrm{st}$ level megacities (Paris, London, Rhine-Ruhr area, Po Valley) (van der Gon et al., 2009). Additionally to the pollutant emission inventory an anthropogenic heat flux (AHF) model $(0.25 \times 0.25$ arc-minute resolution) was developed and used to compute the AHF inventories for Europe and London (Allen et al., 2010). Emissions are the focus of WP1, which links to the other aspects of the project as shown in Fig. 3.

WP2 is focusing on the megacity features (e.g. morphology, AHF), along with processes taking place in the urban 
canopy and boundary layer, which are responsible for the airborne transport and transformation of pollutants and urban climate effects. This WP is aimed at the development of databases of morphology/landuse classifications for megacities, as well as developing databases and sub-grid parameterisations of urban layer processes for megacity, regional and global scale models. A morphology database for Paris has been developed (Sievinen et al., 2010), along with a hierarchy of urban canopy and energy budget parameterisations for different scale models (Grimmond et al., 2010; Mahura and Baklanov, 2010), which are being used to evaluate the surface flux balance modelling and urban features needed for climate and air quality models.

Pollutant emissions impact the chemical composition of the atmosphere on different scales. This in turn influences the climate through radiative transfer and effects on clouds and the hydrological cycle (precipitation, etc.). These issues form the core of the project, and are analysed by WPs 3-6 (Fig. 3).

WP3 focuses on the characterization of aerosols and relevant precursors at urban, suburban, and surrounding non-urban areas. Two intensive measurement campaigns were performed around Paris during 1-31 July 2009 and 15 January-15 February 2010 . The campaigns aimed at examining the evolution of aerosols and gas-aerosol interactions in the urban outflow and specifically at better quantifying primary and secondary organic aerosol (SOA) sources for a European megacity. They included 3 primary and 7 secondary fixed ground measurement sites, an aircraft and 5 mobile vans (Beekmann et al., 2010). More than 25 research laboratories participated. It was found that the pollution plume was still well defined at more than $100 \mathrm{~km}$ downwind from the agglomeration, which gives a clear framework for later studying SOA build-up in the plume. Significant new particle formation events were frequently observed during the campaigns. Paris has been chosen mainly because it is a very concentrated European urban pollution hot spot surrounded by rural areas.

The objective of WP4 is to improve understanding and modelling of local and urban-scale impacts of megacity emissions, on the urban and the surrounding area air quality on examples of the four key megacities (Fig. 1). In particular, new physical and chemical parameterisations and zooming approaches (Moussiopoulos et al., 2010; Koraj and Pandis, 2010) have been implemented and are being tested for several megacities, providing information about the relative importance of the various parameterisations when examining megacity air quality and especially its relation to meteorology. Online coupled chemistry-meteorology models with two-way feedbacks (e.g., Korsholm, 2009) were used to analyse effects of urban aerosols on urban microclimate and to classify meteorological patterns favouring development of urban air pollution episodes in European megacities (Baklanov and Mahura, 2010). Urban aerosols were found to significantly affect several meteorological variables (tem- perature, inversion layers, radiation budget, cloud processes, precipitation, fog, etc.) in and far from the megacities due to the direct and indirect effects.

Continental and global scale impacts of megacities on atmospheric composition and climate using a combination of monitoring and modelling tools are considered in WPs 56. These WPs consider also the effects of future climate and emission scenarios. Each WP activity comprises basic research concerning the individual processes critical for understanding the impacts analysed. Additionally, applied research is devoted to building connections between the scales and aspects introduced, and towards developing integrated assessment tools to define impacts and mitigation strategies. Progress was made in developing and evaluating the satellite-based methods for the measurement of tropospheric gases and aerosols, especially $\mathrm{NO}_{2}$, in and around megacities (Wagner et al., 2010). The radiative forcing from megacity emissions on the global scale was examined (Folberth et al., 2010). Generally, megacities contribute about $2-5 \%$ of the total global annual anthropogenic emission fluxes for various compounds. Megacity pollutants were found to contribute a radiative forcing of $+6.3 \pm 0.4 \mathrm{~mW} / \mathrm{m}^{2}$ from an increase in the ozone burden, while the impact on $\mathrm{CH}_{4}$ contributes a forcing of $-1.0 \pm 0.5 \mathrm{~mW} / \mathrm{m}^{2}$. The aerosol forcing from megacity pollutants amounts to $-8.0 \pm 1.6 \mathrm{~mW} / \mathrm{m}^{2}$ under present-day conditions.

The information from WPs $1-6$ is brought together in WPs 7-8. In WP7 the information and model developments are used to develop integrated tools for prediction of megacity impacts on air quality. Progress has been made on producing a European framework for online and offline coupling of meteorological and atmospheric chemical transport models (Baklanov, 2010). The integrated methodology will be implemented to assess the air quality and climate impacts of selected world megacities by employing improved multiscale air quality and climate models (urbanized, online and off-line coupled, one- and two-way nested). In addition, the results of the atmospheric and climate modelling are used to estimate and assess (in monetary terms) impacts on human health and ecosystems and climate change impacts of megacities with a methodology developed in WP8. Finally, the information from the integrated assessments will be input into WP8, focusing on mitigation options, which will be assessed by creating scenarios of possible future developments of megacities, in which these options are implemented. The emissions for these scenarios are calculated in WP1 and used as input for the integrated modelling. By comparing the results, the different scenarios and policy options are assessed.

MEGAPOLI follows a pyramid strategy (Baklanov et al., 2008) of undertaking detailed measurements in one European major city (Paris), performing detailed analysis for the four 1st level megacities (Fig. 1) and twelve 2nd level megacities with existing air quality datasets, and investigating the effects of all megacities on climate. The results will be disseminated to authorities, policy community, researchers and 
the other stakeholders in the corresponding megacities with aim to improve predicting megacity environment for the future. Results and instruments will support the definition of areas and scales of effective measures to improve present and future air quality in large urban agglomerations.

\section{Summary and expected impacts}

The MEGAPOLI project (http://megapoli.info) is contributing to the strategic goal of promoting sustainable management of the environment and its resources. It will do this by advancing our knowledge on possible interactions between air quality, climate and human activities related to large urban centres and hotspots. Megacities constitute major sources of anthropogenic air pollution and hence, affect the lives of hundreds of millions of people in the world directly by the quality of air that they breathe and through complex interactions resulting in climate change. Research within this project will lead to improved modelling and assessment tools. In particular, MEGAPOLI will formulate a European methodology for integrated air quality and climate assessment over multiple scales (urban to global).

MEGAPOLI places emphasis on the interactions between air quality and climate change impacts resulting from megacities on regional to global scales and potential mitigation options. It will further lead to an integrated methodology and corresponding tools to assess these impacts not only in $\mathrm{Eu}-$ rope but also elsewhere.

MEGAPOLI will lead to significant scientific innovations including:

i. Integration of the interactions and processes affecting air quality and climate change on regional to global scales coupled with the capability of estimating the human, ecosystem and economic impact of air pollution resulting from megacities;

ii. Development of an integrated European methodology and tools to assess the impacts within and from megacities on city to global scales;

iii. Integration of ground-based, aircraft and satellite technologies with state-of-the-art modelling tools;

iv. Integrated approaches for addressing the feedbacks and interlinkages between climate change and regional air quality related to megacities;

v. Integration of knowledge and practical implementation of improved tools according to level of complexity to the main megacities and hotspots in focus;

vi. Improved current and future emission estimates for natural and anthropogenic sources of air pollutants;

vii. Development of an integrated assessment methodology for supporting EU and global policy frameworks. This will be achieved through the assessment of mitigation options and the quantification of impacts from polluted air-masses on larger scale atmospheric dynamics;

viii. Examination of the important feedbacks among air quality, climate and climate change;

ix. A robust, global information dissemination gateway on air quality, climate change and mitigation and policy options for European stakeholders strengthening the European Research Area.

MEGAPOLI will significantly extend the current state-ofthe-art in the assessment capabilities by developing and implementing reliable integrated tools on multiple scales and for multiple pollutants. These will be applied to assess directly the impact of the largest urban centres and hotspots in Europe and globally by employing highly advanced as well as simpler tools. The project brings together current off-line approaches as well as new on-line methods enabling feedbacks to be quantified on multiple scales enabling mitigation options to be examined more effectively.

Acknowledgements. The research leading to these results has received funding from the European Union's Seventh Framework Programme FP/2007-2011 within the project MEGAPOLI, grant agreement no. 212520 .

Edited by: M. Piringer

Reviewed by: A. N. Skouloudis and another anonymous referee

\section{References}

Allen, L., Beevers, S., Lindberg, F., Iamarino, M., Kitiwiroon, N., and Grimmond, C. S. B.: Global to City Scale Urban Anthropogenic Heat Flux: Model and Variability, Deliverable 1.4, MEGAPOLI Scientific Report 10-01, MEGAPOLI-04-REP2010-03, ISBN 978-87-992924-4-8, 87 pp., 2010.

Baklanov, A. (Ed.): Framework for Integrating Tools, Deliverable D7.1, MEGAPOLI Scientific Report 10-11, MEGAPOLI-14REP-2010-03, ISBN 978-87-993898-4-1, 68 pp., 2010.

Baklanov, A. and Mahura, A. (Eds.): First Year MEGAPOLI Dissemination Report, Deliverable 9.4.1, MEGAPOLI Scientific Report 09-03, MEGAPOLI-03-REP-2009-12, ISBN 97887-992924-3-1, 57 pp., 2009.

Baklanov, A. and Mahura, A. (Eds.): Interactions between Air Quality and Meteorology, Deliverable D4.3, MEGAPOLI Scientific Report 10-10, MEGAPOLI-13-REP-2010-03, ISBN 97887-993898-3-4, 48 pp., 2010.

Baklanov, A., Lawrence, M., and Pandis, S.: MEGAPOLI Description of Work (2008-2011), Copenhagen, ISBN 978-87-9929240-0, 150 pp., 2008.

Beekmann, M., Baltensperger, U., and the MEGAPOLI campaign team: Database of Chemical Composition, Size Distribution and Optical Parameters of Urban and Suburban PM and its Temporal Variability (Hourly to Seasonal), Deliverable D3.1, MEGAPOLI Scientific Report 10-15, MEGAPOLI-18-REP-2010-10, http:// megapoli.dmi.dk/publ/MEGAPOLI_sr10-15.pdf, 21 pp., 2010. 
Folberth, G., Rumbold, S., Collins, W. J., and Butler, T.: Determination of Radiative Forcing from Megacity Emissions on the Global Scale, Deliverable D6.2, MEGAPOLI Scientific Report 10-08, MEGAPOLI-11-REP-2010-03, ISBN 978-87-993898-10, 19 pp., 2010.

Grimmond, C. S. B., Blackett, M., and Best, M. J.: Urban Energy Balance Models Comparison, Deliverable D2.3, MEGAPOLI Scientific Report 10-07, MEGAPOLI-10-REP-2010-03, ISBN 978-87-993898-0-3, 72 pp., 2010.

Koraj, D. and Pandis, S. N.: Evaluation of Zooming Approaches Describing Multiscale Chemical Transformations, Deliverable D4.2, MEGAPOLI Scientific Report 10-05, MEGAPOLI-08REP-2010-01, ISBN 978-87-992924-8-6, 29 pp., 2010.

Korsholm, U.: Integrated modeling of aerosol indirect effects - development and application of a chemical weather model, $\mathrm{PhD}$ thesis University of Copenhagen, Niels Bohr Institute and DMI, Research Department, http://www.dmi.dk/dmi/sr09-01. pdf, 2009.

Mahura, A. and Baklanov, A. (Eds.): Hierarchy of Urban Canopy Parameterisations for Different Scale Models, Deliverable D2.2, MEGAPOLI Scientific Report 10-04, MEGAPOLI-07-REP2010-03, ISBN 978-87-992924-7-9, 50 pp., 2010.
Moussiopoulos, N., Douros, J., and Tsegas, G. (Eds.): Evaluation of Zooming Approaches Describing Multiscale Physical Processes, Deliverable D4.1, MEGAPOLI Scientific Report 1003, MEGAPOLI-06-REP-2010-01, ISBN 978-87-992924-6-2, $41 \mathrm{pp} ., 2010$.

Sievinen, P., Hellsten, A., Praks, J., Koskinen, J., and Kukkonen, J.: Urban Morphological Database for Paris, France, Deliverable D2.1, MEGAPOLI Scientific Report 10-02, MEGAPOLI05-REP-2010-03, ISBN 978-87-992924-5-5, 13 pp., 2010.

van der Gon Denier, H. A. C., Visschedijk, A. J. H., van der Brugh, H., Dröge, R., and Kuenen, J.: A base year (2005) MEGAPOLI European gridded emission inventory (1st version), Deliverable 1.2, MEGAPOLI Scientific Report 09-02, MEGAPOLI-02-REP2009-10, ISBN 978-87-992924-2-4, 17 pp., 2009.

Wagner, T., Beirle, S., and Shaiganfar, R.: Characterization of Megacity Impact on Regional and Global Scales Using Satellite Data, Deliverable D5.1, MEGAPOLI Scientific Report 1009, MEGAPOLI-12-REP-2010-03, ISBN 978-87-993898-2-7, 25 pp., 2010. 